\title{
Research on the Rock Pressure Behavior at Close-Distance Island Working Faces under Deep Goaf
}

\author{
Shoulong $\mathrm{Ma} \mathbb{1}^{1,2}$ \\ ${ }^{1}$ School of Civil Engineering and Architecture, Anhui University of Science and Technology, Huainan, Anhui 232001, China \\ ${ }^{2}$ China Coal Xinji Energy Co.,Ltd., Huainan, Anhui 232001, China \\ Correspondence should be addressed to Shoulong Ma; 2020100046@aust.edu.cn
}

Received 15 April 2021; Revised 3 August 2021; Accepted 21 August 2021; Published 20 September 2021

Academic Editor: Dezhong Kong

Copyright (c) 2021 Shoulong Ma. This is an open access article distributed under the Creative Commons Attribution License, which permits unrestricted use, distribution, and reproduction in any medium, provided the original work is properly cited.

In order to realize the safe and efficient mining of the short-distance isolated island working face under the deep goaf area, the 120502 isolated island working face of Liuzhuang Mine was taken as the engineering background. The method of combining numerical simulation and field measurement were used comprehensively to systematically simulate and study the spatial evolution of the stress field, plastic strain field, and fracture field of coal rock during the mining process. The leading support pressure and the vertical displacement of the roof in the overlapping section and noncoinciding section of the isolated working face and the goaf above were measured on site. The results are that the peak value of the advanced support pressure of the overlap section and the nonoverlapping section is $10 \mathrm{~m}$ before the coal wall of the working face; the advanced support pressure of the nonoverlapping section is $33.3 \mathrm{MPa}$, and the vertical displacement of the roof is $300 \mathrm{~mm}$. The advanced support pressure and the vertical displacement of the roof in the noncoincidence section were significantly higher than those in the coincidence section of 18.2 $\mathrm{MPa}$ and $210 \mathrm{~mm}$. The results are consistent with those predicted by numerical simulation. This provides theoretical support for the safe mining of the 120502 isolated island working face in Liuzhuang Mine and, at the same time, provides a reference for the study of similar working faces in other domestic mining areas.

\section{Introduction}

As the mining of coal resources in our country continues to move to the depths, due to the influence of geological conditions and the need for safe mining in the mines, it is inevitable that deep mine isolated islands are formed [1-4]. The coal rock masses in many mines have a certain tendency to impact, so the mining of isolated island working faces will encounter more complicated safety problems. Due to the open space on both sides of the isolated working face, the surrounding rock of the roadway is under a high-stress environment for a long time. As a result, the pressure of the mine becomes obvious, and the surrounding rock is deformed and damaged seriously [5-7]. It is difficult to support and maintain the two lanes and the open-off cut. The adjacent rock mass is in a rheological state after being destroyed and affected by dynamic pressure. Therefore, the behavior of mine pressure is complicated, which affects the safe advancement of the working face [8]. To this end, researchers have conducted a lot of research on the behavior of rock pressure on the isolated island working face and rock burst problems.

Liu et al. [9] and $\mathrm{Lu}$ and Shi [10] analyzed the support pressure distribution characteristics of the ultralong-isolated island working face and the rock pressure behavior when the island working face crosses the fault structure. Wang et al. [11] established a thin plate mechanics model and analyzed the distribution behavior of the roof bending moment of the isolated island working face. Wang et al. $[12,13]$ studied the behavior of rock pressure in the short-walled coal pillar working face of an isolated island. Zhao et al. [14] studied the behavior of rock pressure in a typical coal seam island face in western China. Yang et al. [15] comprehensively considered overlying rock movement, geological structure, mining and space, and other factors and classified isolated working faces based on scour prevention. The isolated island working face 
is divided into six types: full mining, insufficient mining, full-insufficient mining, three-dimensional, "recessive," and compound type. In order to carry out the prevention and control of rock burst in different types of isolated island working faces, Dou [16, 17] proposed the detection and prediction and control technology of rock burst hazard in isolated island working face [18-20]. Wang et al. [21] analyzed the roof rupture height of the isolated island working face and the temporal and spatial distribution characteristics of microseismic events in the "square" area of the working face. Zhang et al. [22] used elastic plate theory to analyze the elastic energy value released during the fracture of the hard roof and used FLAC ${ }^{3 \mathrm{D}}$ numerical simulation to divide the high-stress area during the mining face. At the same time, according to the fractal theory, the internal correlation between the time distribution and spatial distribution of microseismic events and rock bursts was analyzed.

The above research studies have analyzed the appearance behaviors of rock pressure in different types of isolated island working faces and the prevention and control of rock bursts and have achieved good results. However, there is little research on island working faces under some complex conditions, especially those under the goaf. Based on the engineering background of 120502 isolated island working face in Liu Zhuang Coal Mine, this paper analyzes the behavior of underground pressure on the isolated island working face under the goaf of the deep close coal seam group through numerical simulation and field measurement.

\section{Project Overview}

The research working face is 120502 isolated island working face of Liu Zhuang Coal Mine. 120502 isolated island working face is located in the first level and second mining area. The south of the working face is the goaf of 120503 working face, the north is near the goaf of 120501 working face, and the above is the 6-1 and 8 coal goaf. Also, the vertical distance between the overlying 6-1\# coal seam goaf and the $5 \#$ coal seam is $18 \mathrm{~m}$, which is an isolated island working face under the short-distance goaf. The specific spatial position relationship is shown in Figure 1.

The 120502 working face is a monoclinic structure with an average dip angle of $13.0^{\circ}$, the coal thickness of the working face is $0.98 \sim 5.58 \mathrm{~m}$, and the average thickness is $4.05 \mathrm{~m}$. 120502 working face 5 coal false roof is not developed, the direct roof is mudstone, the upper part contains a small amount of sandy content, and the average thickness is $8.73 \mathrm{~m}$. The main roof is fine sandstone. The geological histogram of the coal roof and floor of the working face is shown in Figure 2. This working face is a low-gas working face, and the coal seam is easy to combust spontaneously.

\section{Numerical Simulation}

In order to simulate the stress and deformation characteristics of the overlying strata in different spatial layers during the mining process and to reproduce the spatial change process of the entire overlying strata movement and deformation, this paper uses FLAC ${ }^{3 \mathrm{D}}$ software to carry out a numerical simulation.

3.1. Model Building. A numerical model is established on the fully mechanized mining face of the 120502 isolated island with main goafs on the left, right, and upper sides, The model is $550 \mathrm{~m}$ long, $360 \mathrm{~m}$ wide, and $200 \mathrm{~m}$ high. The Mohr-Coulomb constitutive model is adopted for coal and rock mass, and its physical and mechanical parameters are shown in Table 1.The characteristics of the top and bottom of the working face are shown in Figure 2. Displacement boundary conditions are applied around the model, and the upper part of the model is free boundary conditions. A vertical stress of $25.1 \mathrm{MPa}$ is applied at the top of the model, a stress of $30.2 \mathrm{MPa}$ is applied at the bottom, and the surrounding stress is $42.3 \mathrm{MPa}$ According to the geological and ground stress test report of the working face, considering the elevation of the working face and the weight of the model, a vertical stress of $9 \mathrm{MPa}$ was applied to the top of the model. The elastoplastic model is adopted, and the Mohr-Coulomb failure criterion is selected. The specific mechanical parameters of the main coal and rock layers are shown in Table 1.

3.2. Simulation Scheme. In the process of numerical simulation, in order to correctly simulate the stress, displacement, and fracture deformation characteristics of the surrounding rock of the stope caused by the stopping of the isolated working face, the model reaches the initial stress balance state under the given ground stress and boundary conditions. According to the sequence of the stope, the 120501, 120601, and 120503 working faces were excavated to construct a "three-sided" isolated island working face. The stopping of the 120502 mining working face is performed step by step. The stopping distances are, respectively, $80 \mathrm{~m}$, $130 \mathrm{~m}, 180 \mathrm{~m}$, and $240 \mathrm{~m}$, and each excavation is designed to be 3000 steps. The distribution characteristics of stress, displacement, and plastic zone during the mining process are studied from the two directions of working face inclination and alignment direction. And, the distribution cloud map is quantified, so as to conduct in-depth research on the deformation characteristics of the overlying rock fractures during the stopping process of the isolated working face.

\subsection{Simulation Result Analysis}

3.3.1. Analysis of Evolution Characteristics of Mining Stress Field. After the model starts excavating, the stress distribution characteristics of the central coal rock mass in the inclined direction at the coal wall position at different advancing distances are shown in Figure 3. The pressure relief area in the inclined direction moves upward in an arch shape as the mining distance increases and gradually merges into one body. The coal pillar on the right side of the working face has a high degree of stress concentration, and the stress concentration factor has been increased from 2.54 to 4.41. Because the coal pillar on the left is in the pressure relief 


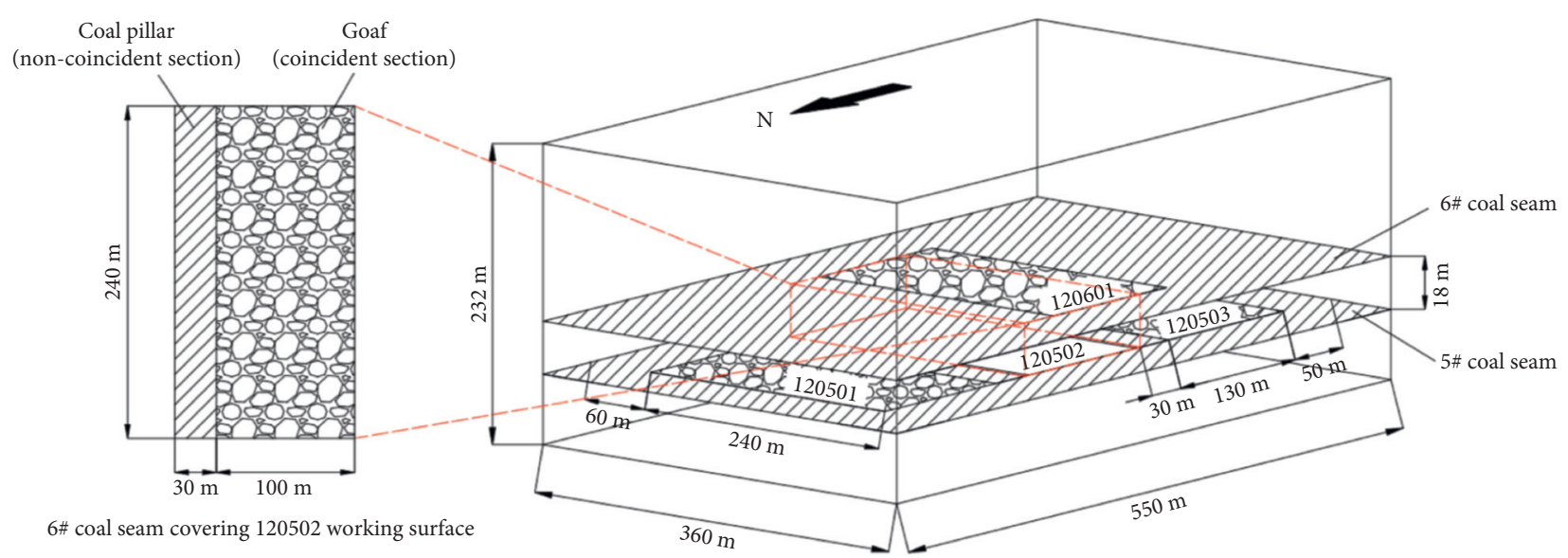

FIGURE 1: The spatial position relationship of each working face in the mining area.

\begin{tabular}{|c|c|c|}
\hline Column & Rock name & Thickness (m) \\
\hline & Mudstone & 4.15 \\
\hline & Fine sandstone & 4.20 \\
\hline & Sandy mudstone & 5.10 \\
\hline 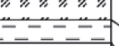 & Siltstone & 2.70 \\
\hline & Mudstone & 2.00 \\
\hline & Fine sandstone & 1.70 \\
\hline & Mudstone & 2.22 \\
\hline & Fine sandstone & 4.00 \\
\hline & 6\# coal seam & 1.50 \\
\hline & Fine sandstone & 9.40 \\
\hline & Mudstone & 8.73 \\
\hline & 5\# coal seam & 4.05 \\
\hline & Mudstone & 1.45 \\
\hline & $\begin{array}{l}\text { Medium-fine } \\
\text { sandstone }\end{array}$ & 13.6 \\
\hline
\end{tabular}

Figure 2: Geological histogram of coal roof and floor.

Table 1: Physical and mechanical parameters of rock mass used in calculation.

\begin{tabular}{|c|c|c|c|c|c|c|}
\hline $\begin{array}{l}\text { Rock formation } \\
\text { name }\end{array}$ & $\begin{array}{c}\text { Bulk density, } \gamma \\
\left(\mathrm{kg} / \mathrm{m}^{3}\right)\end{array}$ & $\begin{array}{c}\text { Bulk modulus, } K \\
(\mathrm{GPa})\end{array}$ & $\begin{array}{c}\text { Shear modulus, } G \\
(\mathrm{GPa})\end{array}$ & $\begin{array}{c}\text { Cohesion, } c \\
(\mathrm{MPa})\end{array}$ & $\begin{array}{c}\text { Internal friction } \\
\text { angle, } \varphi\left(^{\circ}\right)\end{array}$ & $\begin{array}{l}\text { Tensile strength, } \sigma_{b} \\
(\mathrm{MPa})\end{array}$ \\
\hline $\begin{array}{l}\text { Middle-fine } \\
\text { sandstone }\end{array}$ & 2580 & 5.6 & 4.2 & 8 & 38 & 3.5 \\
\hline Siltstone & 2680 & 5.6 & 4.2 & 8 & 38 & 3.5 \\
\hline 5 coal & 1410 & 1.73 & 0.82 & 0.18 & 20 & 0.2 \\
\hline 6-1 coal & 1390 & 2.0 & 0.88 & 0.42 & 24 & 0.3 \\
\hline Fine sandstone & 2800 & 16.04 & 12.02 & 3.47 & 43 & 4.96 \\
\hline Mudstone & 2567 & 4.3 & 2.8 & 0.7 & 30 & 1.68 \\
\hline
\end{tabular}

range of the upper goaf, and the stress concentration is relatively weak.

Figure 4 shows the vertical stress distribution cloud diagram in the middle of the goaf in the alignment direction when advancing at different distances. It can be seen from
Figure 1 that the 120502 working face and the 120601 working face are staggered in the horizontal direction. At the square of the working face, affected by the mining of 5th coal, the vertical stress distribution range of the floor rock is enlarged. The concentrated stress inside the coal body at the 


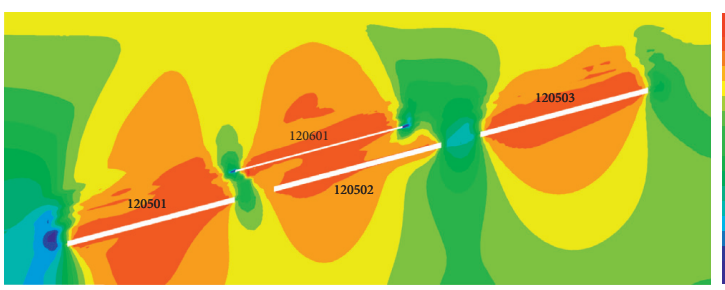

(a)

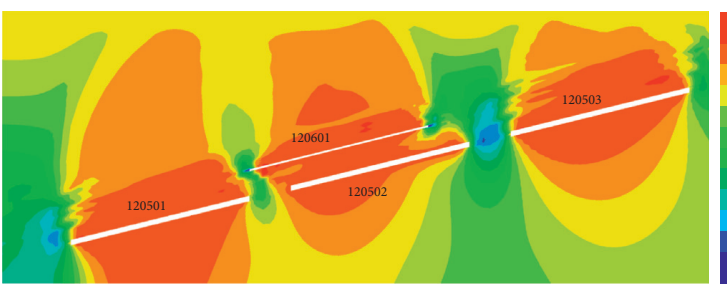

(c)
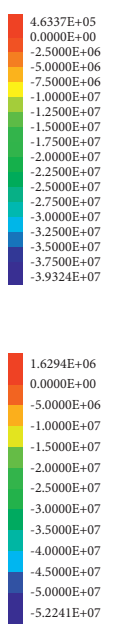

$5.0000+07$

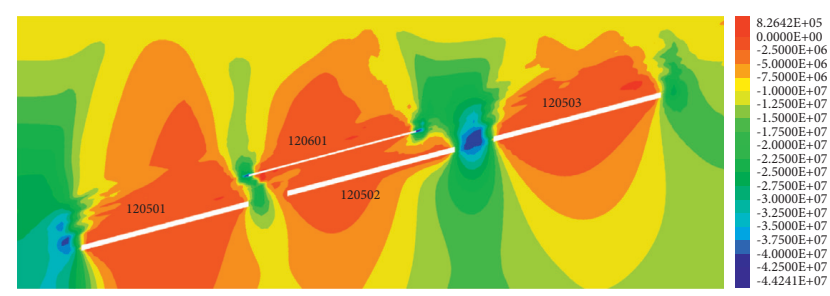

(b)

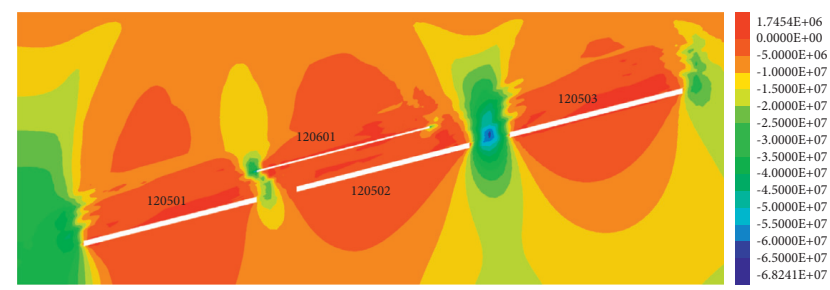

(d)

Figure 3: Cloud diagram of vertical stress distribution (inclination direction). (a) The working face advances $80 \mathrm{~m}$, (b) the working face advances $130 \mathrm{~m}$, (c) the working face advances $180 \mathrm{~m}$, and (d) the working face advances $240 \mathrm{~m}$.

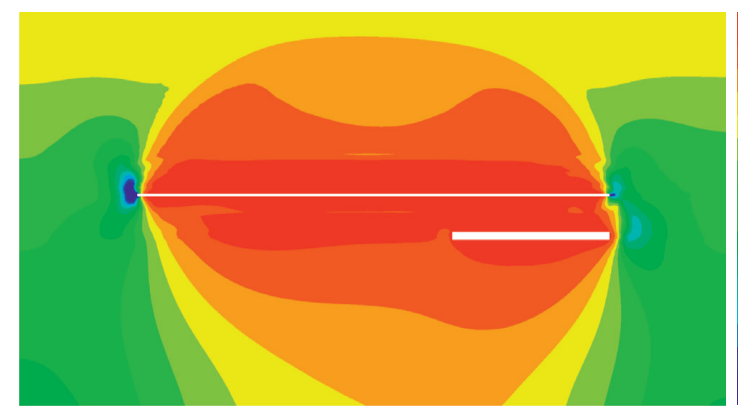

(a)

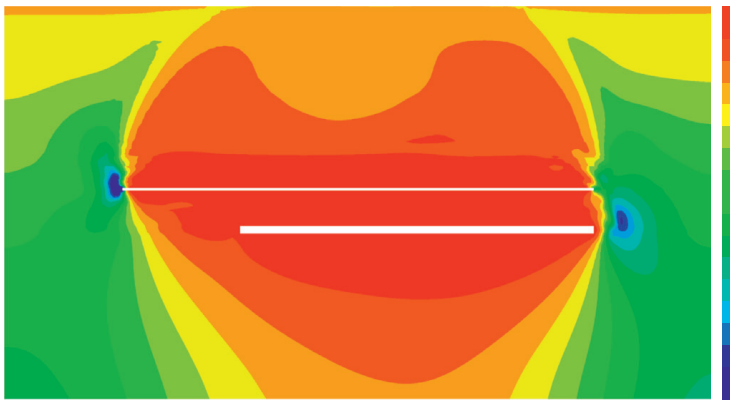

(c)

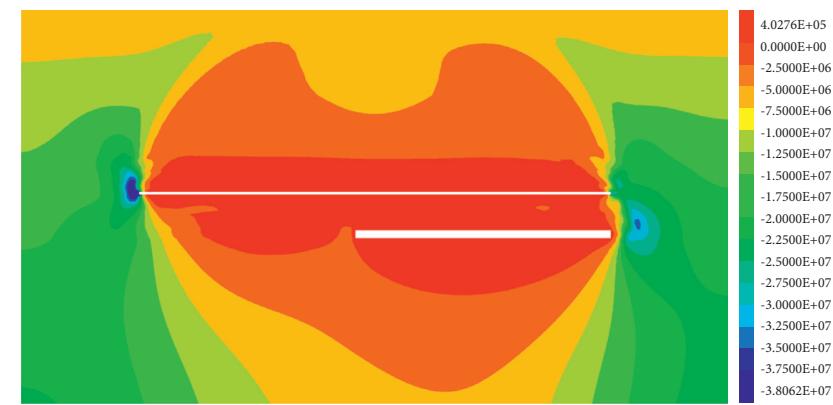

(b)

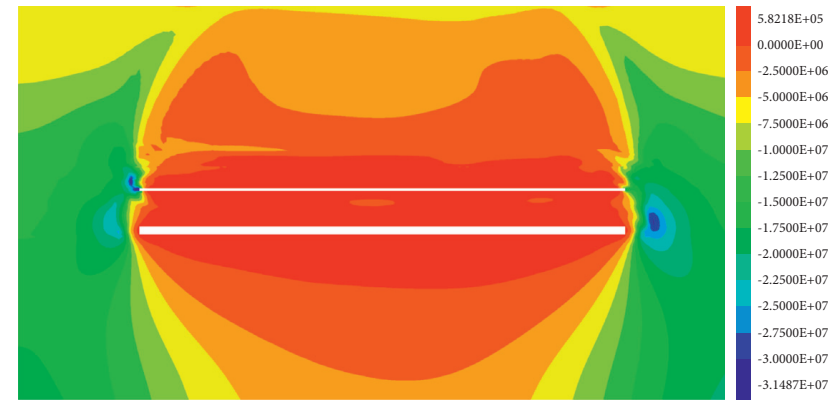

(d)

FIgURE 4: Vertical stress distribution cloud diagram (alignment direction): (a) the working face advances $80 \mathrm{~m}$, (b) the working face advances $130 \mathrm{~m}$, (c) the working face advances $180 \mathrm{~m}$, and (d) the working face advances $240 \mathrm{~m}$.

open-off cut gradually shifted from the 6th coal to the 5th coal, showing that the concentrated stress at the end of the 6 th coal weakened and the concentrated stress at the 5 th coal end increased. The floor is affected by the upper coal mining, and the front of the working face is in the mutual influence area between the pressure relief zone and the concentrated stress zone, and the concentrated stress is not large. When the working face advances to $240 \mathrm{~m}$, the pressure at the end of coal 6 is released. The stress is concentrated at the end of the lower layer coal 5, which increases the concentrated stress and increases the degree of damage.

The overburden strata have basically similar changes in the alignment and inclination directions. The stress concentration area and the stress reduction area are also basically the same, and they are continuously moved and expanded in an arch shape to form connections with other mining areas. The main goafs on the left, right, and above all have an impact on the deformation of the overlying rock in 
the goaf, but the upper main goaf has the greatest disturbance to it.

It can be seen from Figure 5 that, in the alignment direction, in the section overlapping with the upper goaf, the stress concentration areas are behind the open-off cut and in front of the working face. When the mining distance does not exceed $240 \mathrm{~m}$, the distribution in front of the working face will first decrease and then increase. When the mining distance of the working face reaches $240 \mathrm{~m}$, the distribution of "horizontal three areas" appears. The support pressure in front of the working face is increasing, and the distance between the peak support pressure and the coal wall is stable at about $10 \mathrm{~m}$. In the noncoincident zone, it can be seen from Figure 6 that the stress concentration area remains unchanged, and the peak stress concentration is also equivalent under different advancing distances. Compared with the coincident section, the peak support pressure in the front of the working face under the same advance distance is larger. Comparing the two sections, it can be seen that the overburden stress distribution characteristics of the stope in the direction of the coincident and noncoincident sections are basically the same. The areas of stress concentration are both behind the open-off cut and in front of the working face, and the coal rock masses nearby are subject to greater stress, resulting in compression and destruction.

3.3.2. Analysis of Change Characteristics of Mining Displacement Field. Figure 7 reflects the vertical displacement change curve in the direction of the 120502 and 120601 working faces at different advancing distances in the overlapping sections. The direction of the vertical displacement in the section that coincides with the upper goaf in the alignment direction changes from downward to upward, and the vertical upward displacement peak remains stable. The change curve in the noncoincident zone is shown in Figure 8. The upper main golf area has a great influence on the vertical displacement. The peak value of the vertical displacement increases with the increase of the mining distance, and the vertical displacement of the overlying strata in the mined-out area is downward during the whole advancement process.

From the vertical displacement curve during the advancing process of the working face, it can be seen that the vertical displacement of the overburden under different advancing distances forms the largest sinking area in the middle of the mined-out area, resulting in stress concentration in the area behind the open-off cut and near the working front.

It can be seen from Figure 9 that, during the mining process of the working face, the horizontal displacement increases continuously with the advance of the working face in the alignment direction. The changing graphics show curved sinking and symmetrical, with the center of symmetry in the middle of the goaf. The horizontal displacement changes strongly behind the open-off cut and in the goaf area in front of the working face. The horizontal deformation of

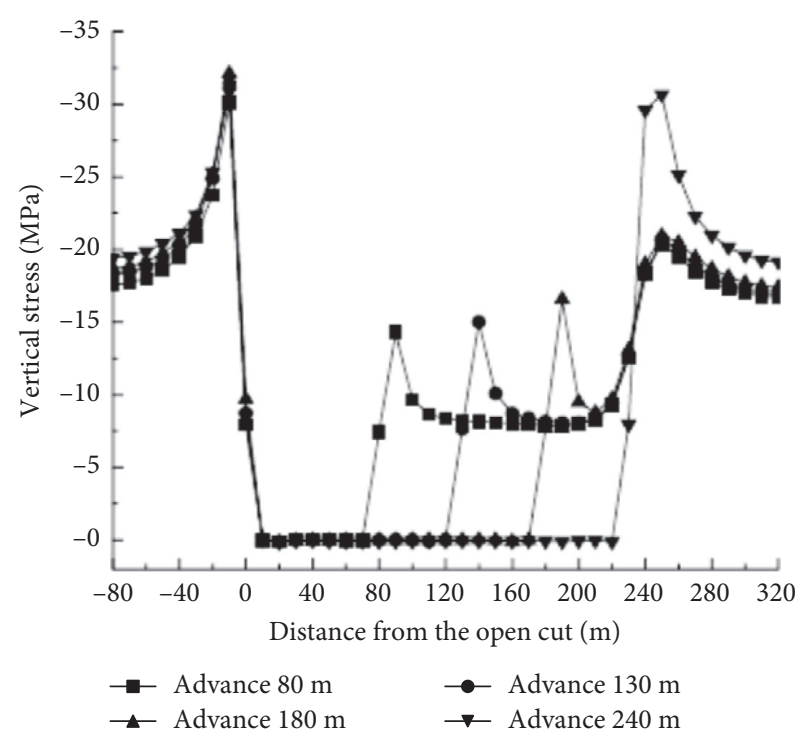

FIGURE 5: The vertical stress distribution curve of the first overlying layer (coincident section).

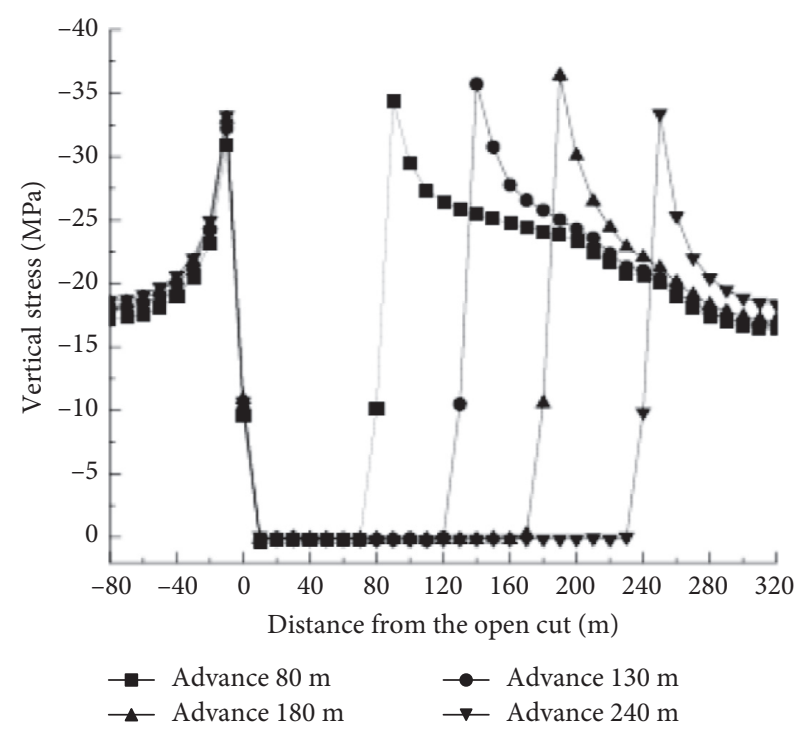

FIgURE 6: Vertical stress distribution curve of the first overlying layer (noncoincident section).

the overlying rock is relatively large, and the overlying rock is subjected to the combined action of horizontal stretching and compression, resulting in more fully developed cracks.

3.3.3. Analysis of Change Characteristics of Overlying Rock Plastic Zone. Figure 10 shows the development of the plastic zone in inclined direction when the working face is advanced at different distances. The closer to the working face, the greater the failure of coal and rock mass. $H$ is the development height of the fracture zone, which is $101 \mathrm{~m}, 119 \mathrm{~m}$, $126 \mathrm{~m}$, and $130 \mathrm{~m}$, respectively. When the upper part of coal reaches a certain height, it basically maintains a stable state. With the advance of the working face, the working face is in 


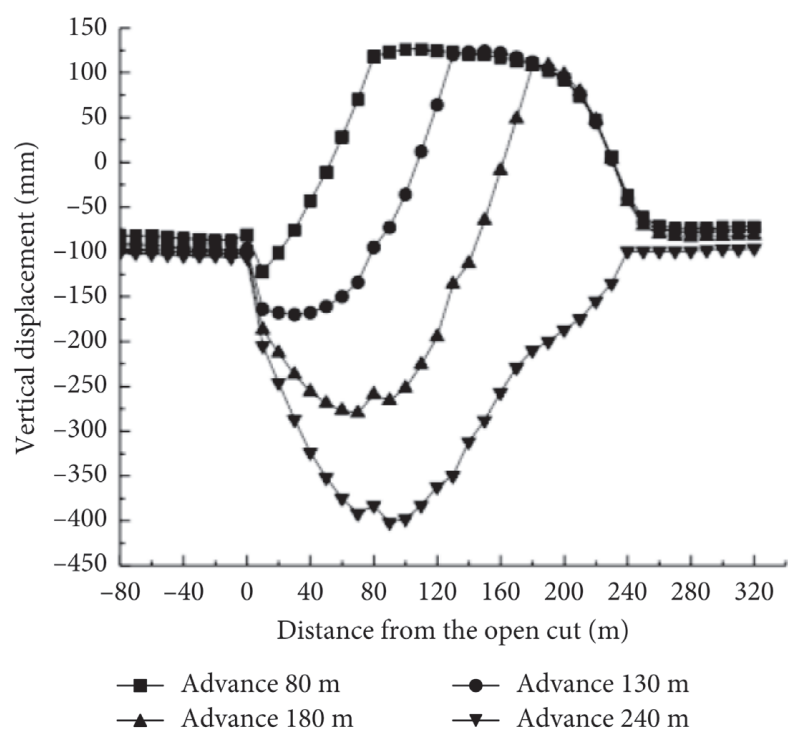

Figure 7: Vertical displacement distribution curve of the first overlying layer (coincident section).

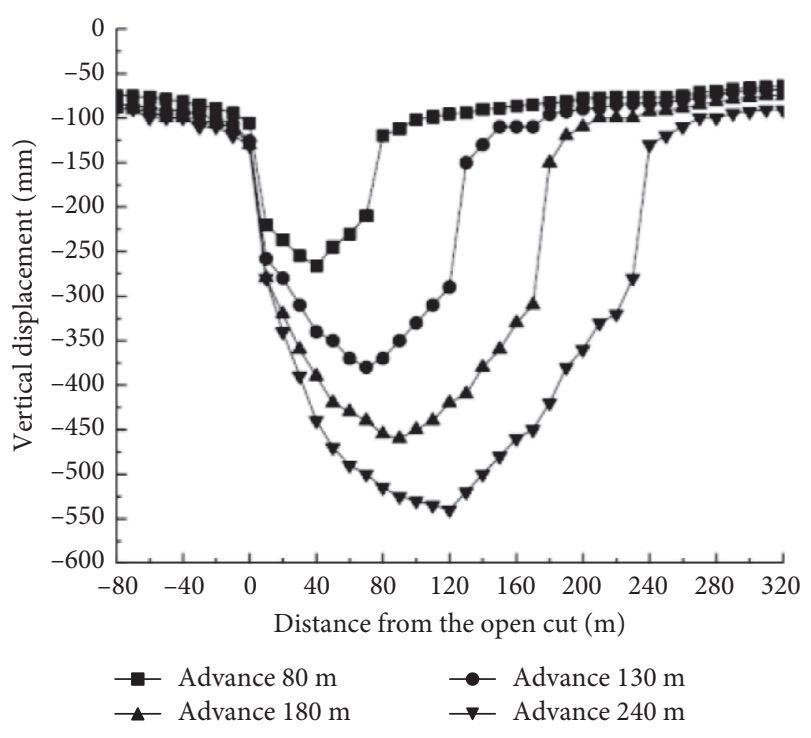

Figure 8: Vertical displacement distribution curve of the first overlying layer (noncoincident section).

the state of nonuniform expansion and dynamic development and gradually intersects with other plastic areas of the goaf. The plastic zones of multiple working faces are interconnected, the rock mass above the roof is in the tensile and compressive stress zone, and the surrounding rock cracks in the goaf are fully developed.

3.3.4. Determination of the Height Range of the Two Zones of the Overlying Strata. The stress discrimination method is used to divide the height range of the caving zone, the fracture zone, and the bending subsidence zone formed by the movement and deformation of the overlying rock during the mining process. The relationship between the principal stress in the middle position of the alignment and

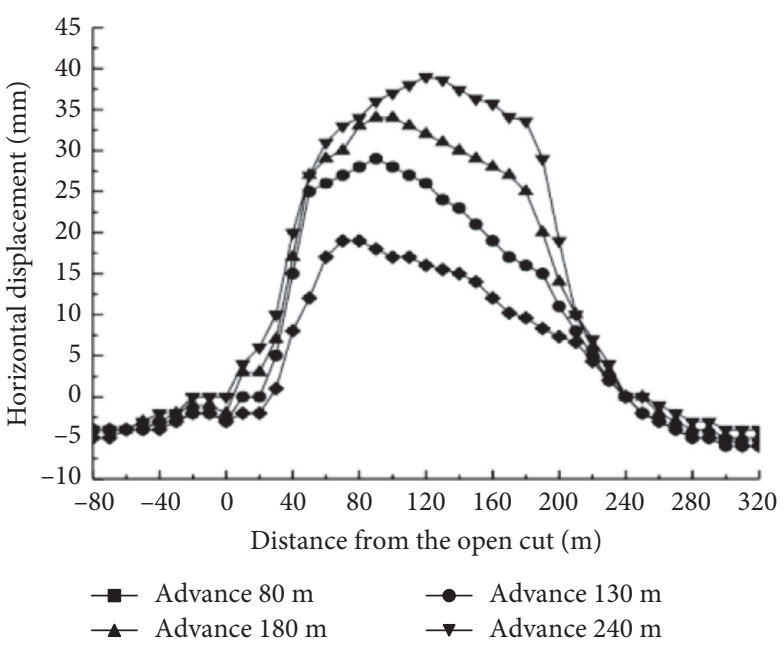

FIgURE 9: Horizontal displacement distribution curve of the first overlying layer (middle position).

the inclination directions and the distance of the roof of the goaf when the working face in the middle position of the overburden strata is mined at different distances is shown in Figure 11 and 12. As the advancing distance of the working face increases, the heights of both the caving zone and the fracture zone show a slight increase trend. In the alignment direction, the height of the caving zone ranges from 6.2 to $8.7 \mathrm{~m}$, and the height of the fracture zone ranges from 33.5 to $38.6 \mathrm{~m}$. In the inclination direction, the height of the caving is in the range of 6.5 to $9.2 \mathrm{~m}$, and the height of the fracture zone is in the range of 34.8 to $40.5 \mathrm{~m}$.

\section{On-Site Measurement and Analysis}

In order to further study the influence of the three-side goaf area in the mining process of the 120502 working face, 


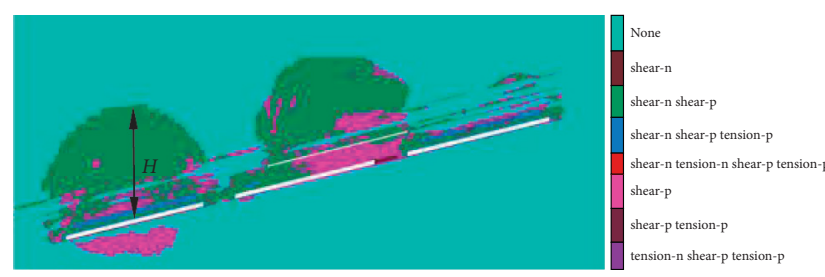

(a)

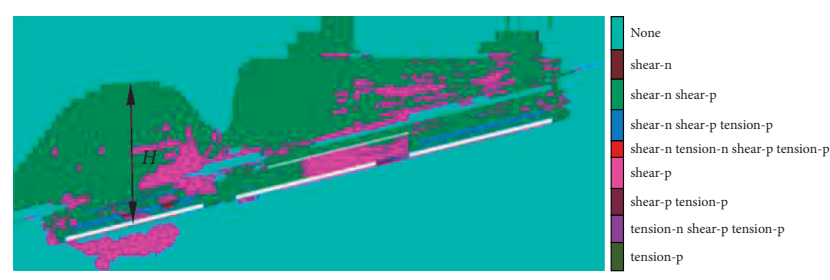

(c)

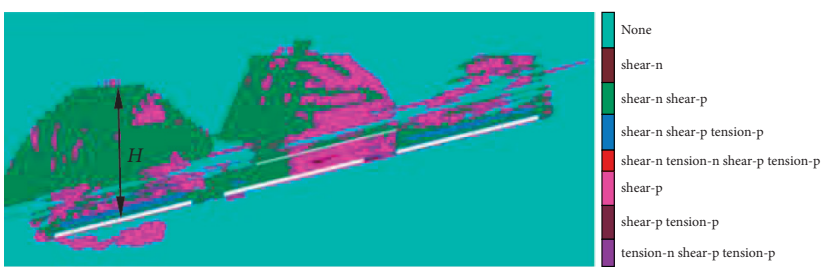

(b)

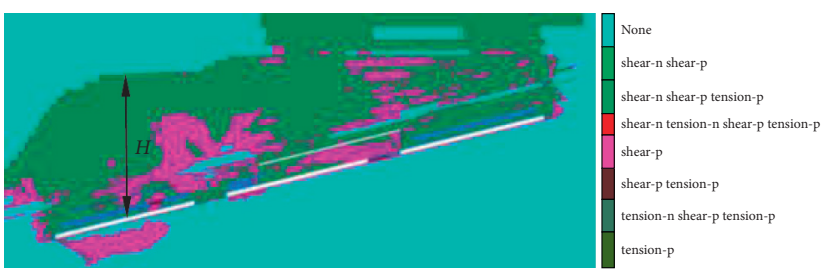

(d)

FIgURE 10: Trend of the plastic zone in the inclination direction: (a) the working face advances $80 \mathrm{~m}$, (b) the working face advances $130 \mathrm{~m}$, (c) the working face advances $180 \mathrm{~m}$, and (d) the working face advances $240 \mathrm{~m}$.

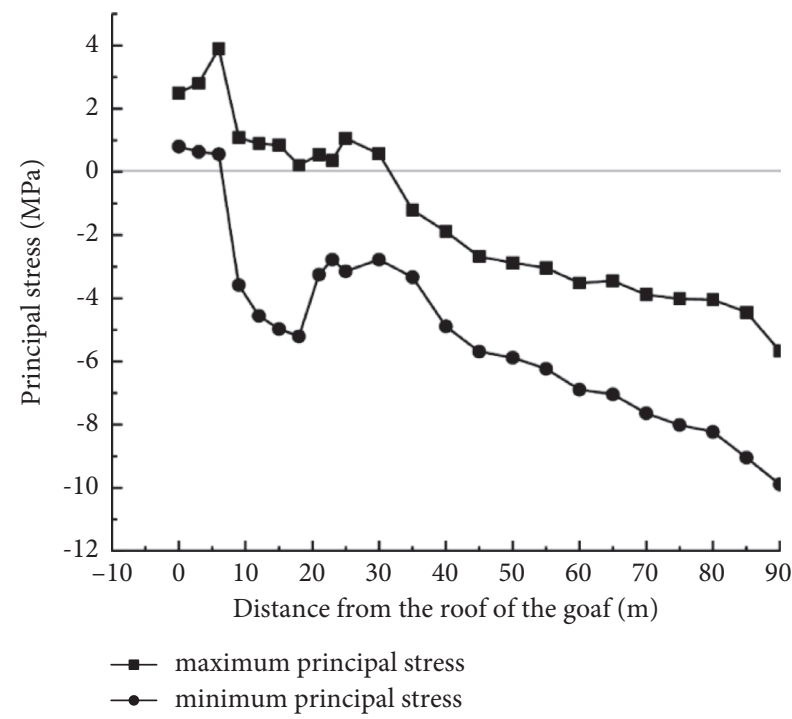

(a)

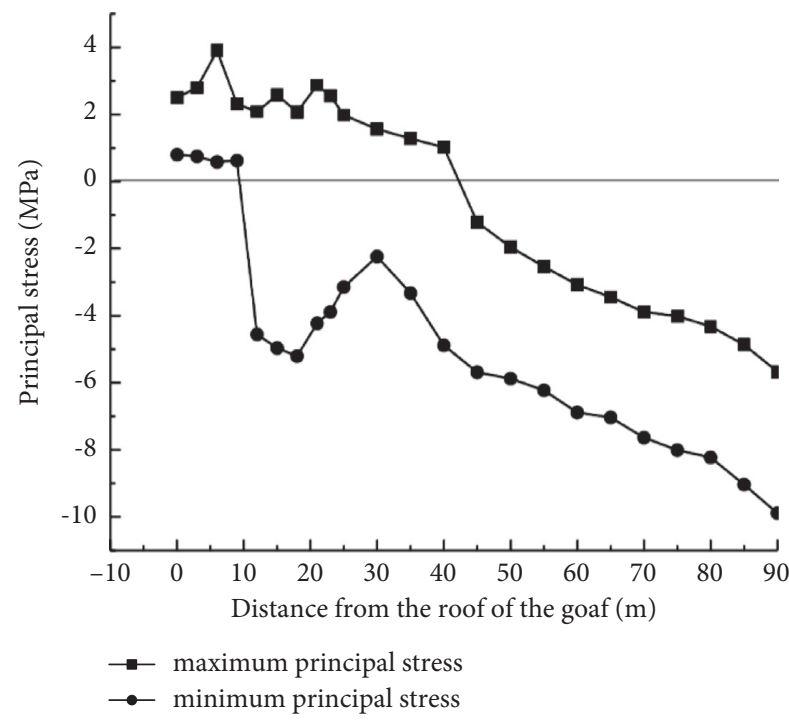

(c)

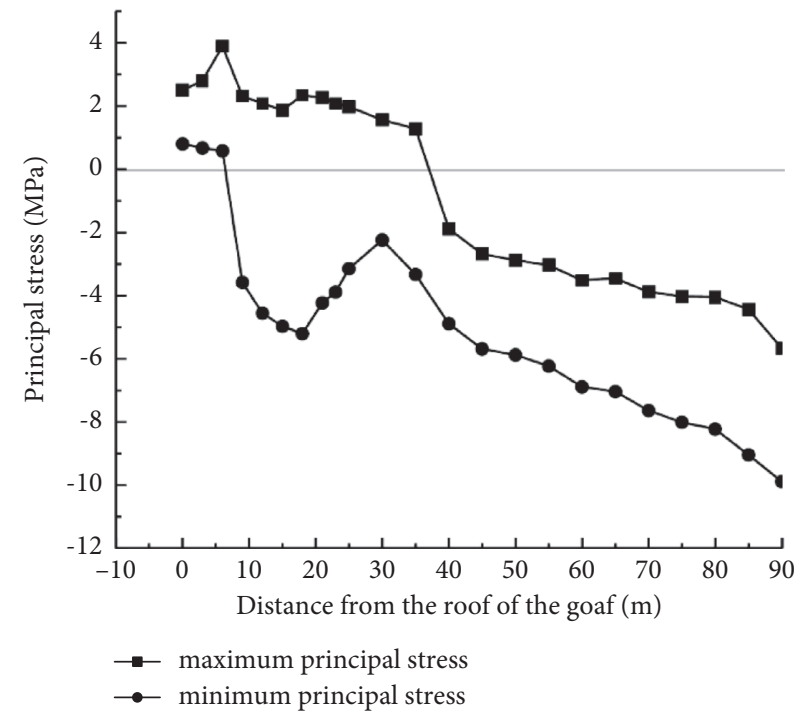

(b)

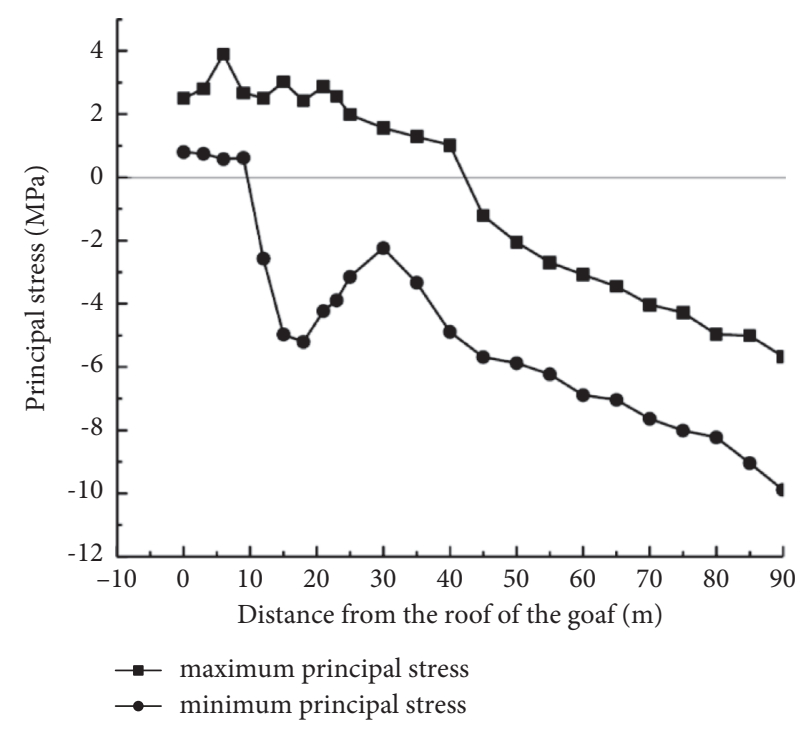

(d)

FIGURE 11: Variation curve of principal stress and the distance from the roof of the goaf (alignment direction): (a) the working face advances $80 \mathrm{~m}$, (b) the working face advances $130 \mathrm{~m}$, (c) the working face advances $180 \mathrm{~m}$, and (d) the working face advances $240 \mathrm{~m}$. 


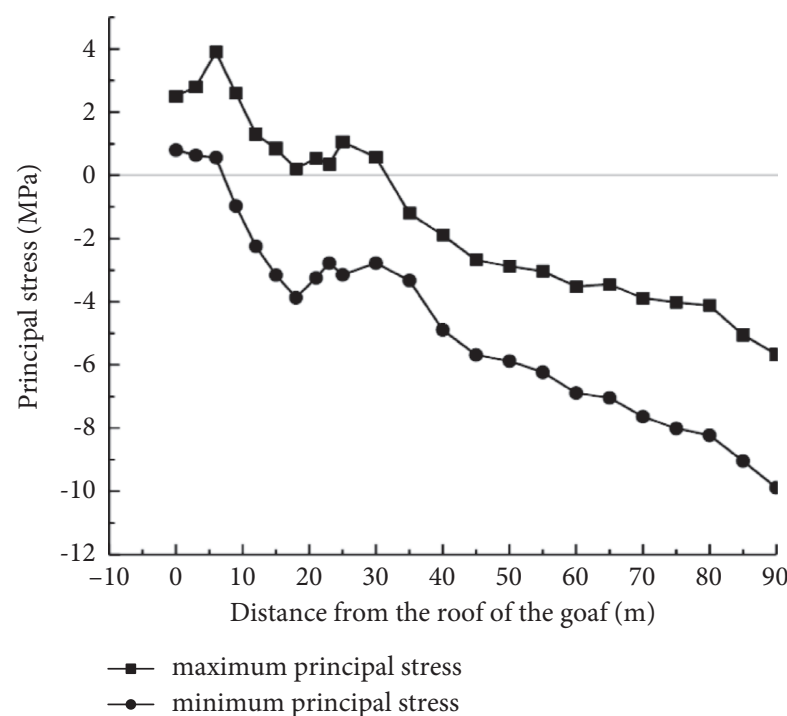

(a)

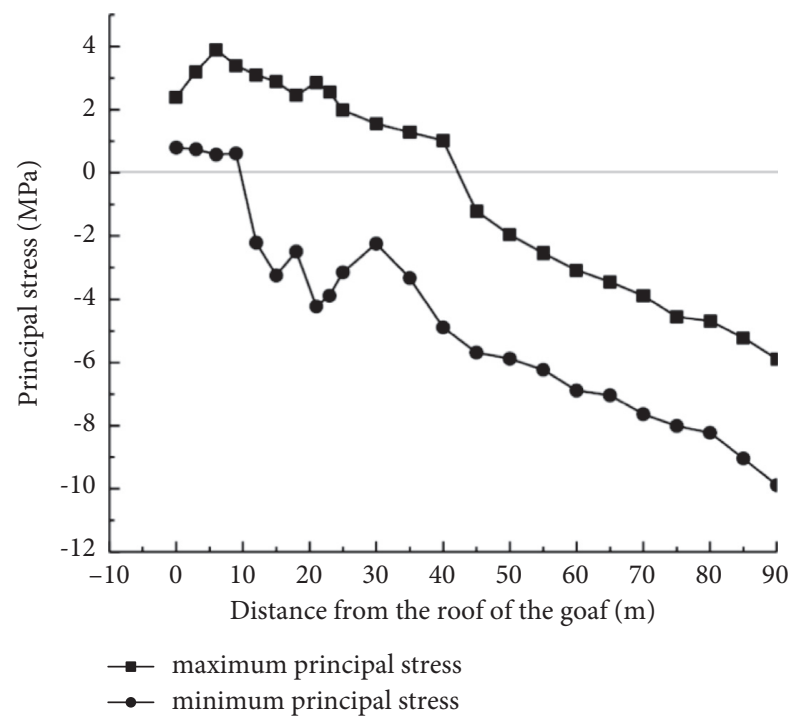

(c)

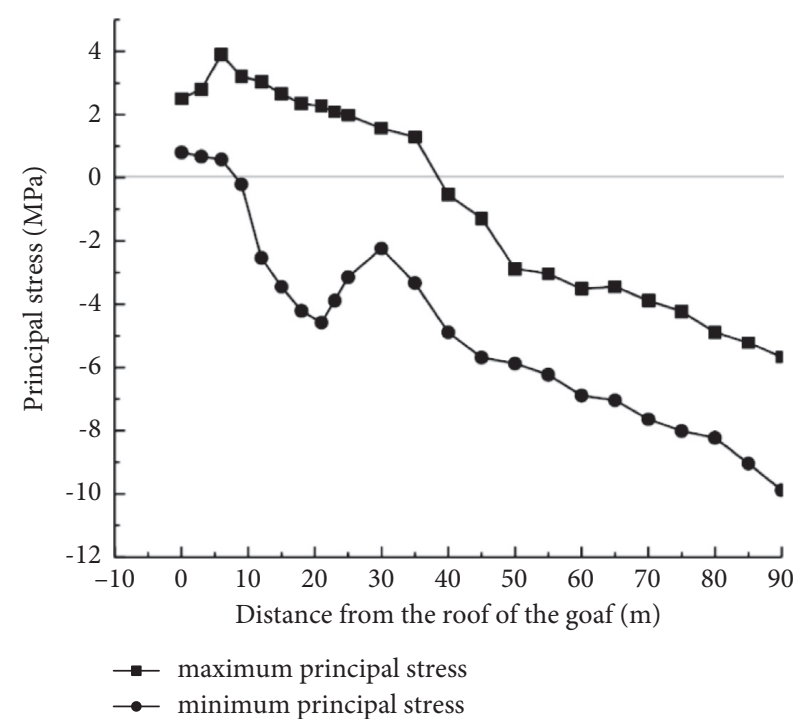

(b)

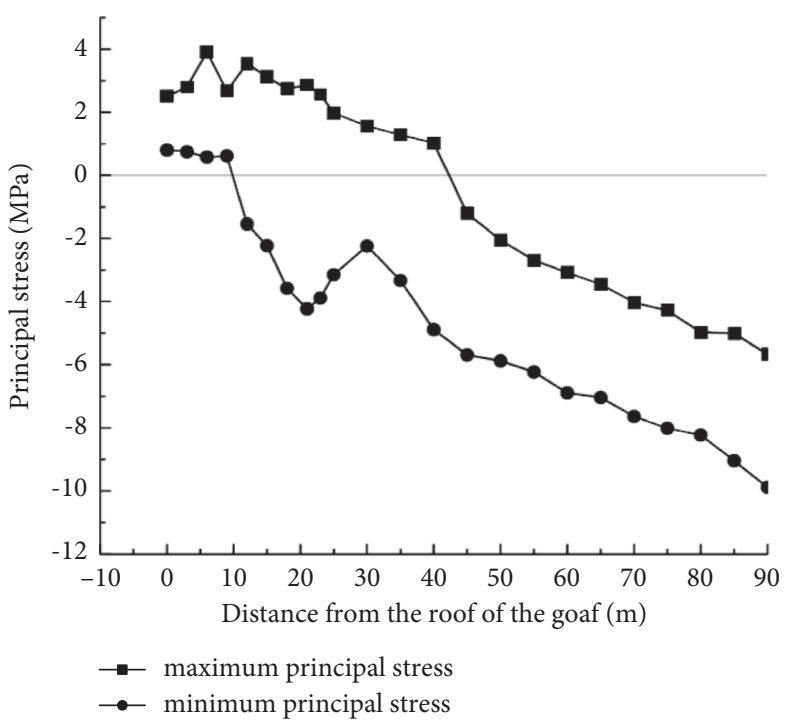

(d)

FIGURE 12: The variation curve of principal stress and the distance from the roof of the goaf (inclination direction): (a) the working face advances $80 \mathrm{~m}$, (b) the working face advances $130 \mathrm{~m}$, (c) the working face advances $180 \mathrm{~m}$, and (d) the working face advances $240 \mathrm{~m}$.

analyze the behavior of the appearance of rock pressure in the overlapping and noncoinciding sections with the upper goaf area, and verify the accuracy of the numerical simulation stress and strain results, on-site monitoring of the leading support pressure and the displacement of the roadway roof at 120502 island working face was conducted.

4.1. Measuring Point Layout and Monitoring Method. The length of the 120502 working face is $400 \mathrm{~m}$. After fully considering the impact of the open-off cut and the stop line to protect the coal pillars, three measurement points for both stress monitoring and displacement monitoring of the working face are, respectively, set up in the transportation roadway and the return air roadway at both ends of the working face. They are located at $100 \mathrm{~m}, 200 \mathrm{~m}$, and $300 \mathrm{~m}$ away from the working face, respectively. The borehole stress gauge was used to measure the advance supporting pressure of the working face, and the roof separation gauge was used to measure the displacement of the surrounding rock of the overlying roof of the roadway.

4.2. Analysis of Monitoring Results of Two Roadways. Figure 13 shows the change curve of the leading support pressure at different advancing distances during the field measurement of the working face. The peaks of the leading support pressure of the working face in the coincident and noncoincident sections are located $10 \mathrm{~m}$ in front of the coal wall. In the overlap section, affected by the pressure relief of the upper goaf, the peak value of the leading support 


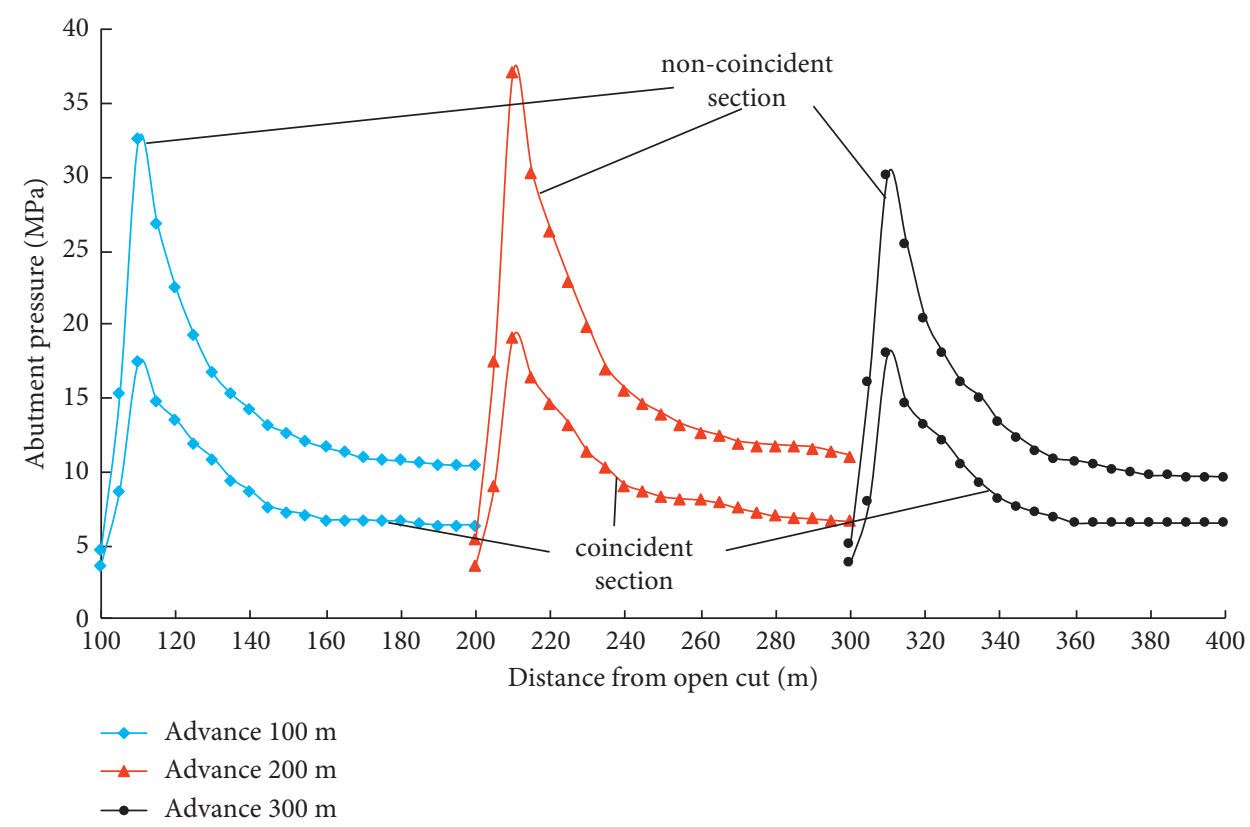

FIgURE 13: The change curve of the leading support pressure.

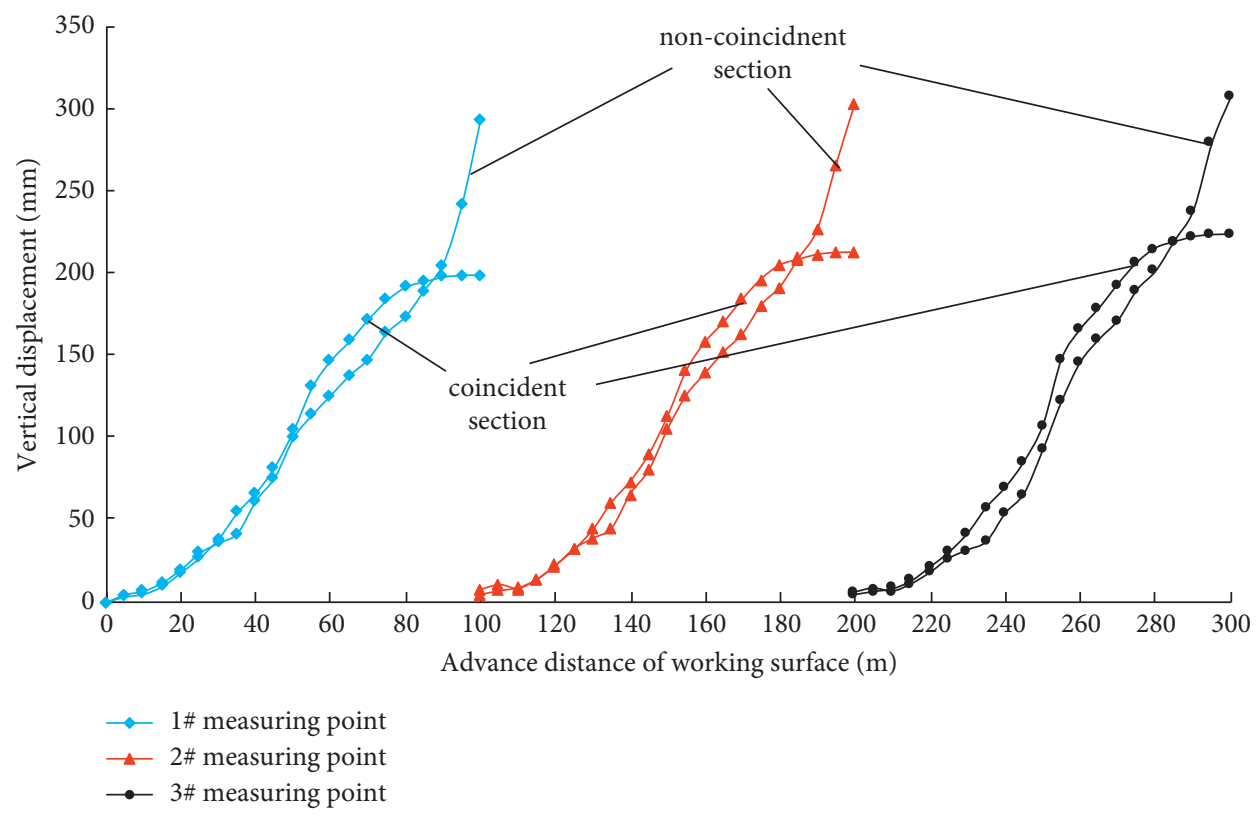

FIGURE 14: Roof displacement variation curve.

pressure is between 17.5 and $19.2 \mathrm{MPa}$, with an average of 18.2 $\mathrm{MPa}$. The peak range of the leading support pressure in the noncoincident section is between 30.2 and 37.1, with an average of $33.3 \mathrm{MPa}$, which is larger than the coincident zone and consistent with the numerical simulation.

The measured vertical displacement curve of the roof of the roadway is shown in Figure 14. In the overlap section, the maximum displacement of the top plate is about $210 \mathrm{~mm}$. The roof displacement of the noncoincident section is obviously larger than that of the coincident section. The displacement is about $300 \mathrm{~mm}$, and it is not stable. It has a tendency to continue to increase as the working face advances, which is consistent with the simulation result.

\section{Conclusions}

(1) During the excavation of isolated island working face, the stress distribution presents the following characteristics. In the inclination direction, the pressure relief area expands with an arch upward movement as the mining distance increases and merges into a "saddle shape". In the alignment direction, in the section coincident with the upper 
goaf, the stress concentration area is behind the open-off cut and in front of the working face. The vertical stress first decreases and then increases with the increase of the mining distance and, finally, presents a "horizontal three-zone" distribution. The support pressure in front of the working face is increasing, and the distance between the peak support pressure and the coal wall is stable at about $10 \mathrm{~m}$. In the noncoincident zone, the stress concentration area remains unchanged, and the peak stress concentration is also equivalent. However, under the same advancing distance, the peak support pressure in front of the work is higher.

(2) The roof displacement has the following characteristics. In the alignment direction, in the section that overlaps with the upper goaf, the vertical displacement direction of the overlying rock strata in the goaf changes from downward to upward, and the peak displacement remains stable. In the noncoincidence section, the vertical displacement of the overlying strata in the goaf is downward, and the peak value is increasing. The horizontal displacement increases continuously with the advancement of the working face in the alignment direction. The overlying rock is subjected to the combined action of horizontal stretching and compression, and thus, the cracks develop more fully. The failure range of the plastic zone is a "saddle shape" with a nonuniform expansion trend and an upward dynamic development. The plastic zone on both sides of the coal pillars has a large development height, while the roof plastic zone has a small development range. With the increase of the advancing distance of the isolated island working face, the height of the caving zone and the fracture zone both show a slight increase trend.

(3) The field measurement shows that the leading support pressure and top plate displacement of the noncoincident section obviously exceed that of the coincident section, and the peaks are all $10 \mathrm{~m}$ in front of the coal wall of the working face. Similarly, the vertical displacement of the roof in the noncoincident section is also greater than that in the coincident section

\section{Data Availability}

The data used to support the findings of this study are available from the corresponding author upon request.

\section{Conflicts of Interest}

The author declares that there are no conflicts of interest regarding the publication of this paper.

\section{Acknowledgments}

This work was supported by the National Natural Science Foundation of China (51404010 and 51374012).

\section{References}

[1] X. F. Liu, E. Y. Wang, E. L. Zhao, and R. X. Shen, "Comprehensive prediction and effect verification of rock burst hazard in island working face," Journal of Mining and Safety Engineering, vol. 27, no. 2, pp. 215-218, 2010.

[2] X. Li, F. Pan, H. Li, M. Zhao, L. Ding, and W. Zhang, "Prediction of rock-burst-threatened areas in an island coal face and its prevention: a case study," International Journal of Mining Science and Technology, vol. 26, no. 6, pp. 1125-1133, 2016.

[3] D. Ma, H. Duan, J. Liu, X. Li, and Z. Zhou, "The role of gangue on the mitigation of mining-induced hazards and environmental pollution: an experimental investigation," The Science of the Total Environment, vol. 664, pp. 436-448, 2019.

[4] X. Liu, S. Tu, D. Hao, Y. Lu, K. Miao, and W. Li, "Deformation law and control measures of gob-side entry filled with gangue in deep gobs: a case study," Advances in Materials Science and Engineering, vol. 2021, Article ID 9967870, 13 pages, 2021.

[5] X. Liu, S. Song, Y. Tan et al., "Similar simulation study on the deformation and failure of surrounding rock of a large section chamber group under dynamic loading," International Journal of Mining Science and Technology, vol. 31, no. 3, pp. 495-505, 2021.

[6] X. S. Liu, D. Y. Fang, and Y. L. Tan, New Detecting Method on the Connecting Fractured Zone above the Coal Face and a Case Study, Rock Mechanics and Rock Engineering, 2021.

[7] X. S. Liu, D. Y. Fang, and Y. L. Tan, "Failure evolution and instability mechanism of surrounding rock for close-distance parallel chambers with super-large section in deep coal mines," International Journal of Geomechanics, vol. 21, no. 05, 2018.

[8] F. Lin and H. Y. Rong, "Surrounding rock stress characteristics and support technology of isolated island working face," Coal Engineering, vol. 49, no. 07, pp. 103-105, 2017.

[9] C. Y. Liu, B. X. Huang, X. J. Meng, P. J. Yang, and L. G. Chen, "Research on the abutment pressure distribution law of superlong island fully mechanized caving face," Chinese Journal of Rock Mechanics and Engineering, vol. 26, no. S1, pp. 27612766, 2007.

[10] F. R. Lu and J. C. Shi, "Research on the rules and measures of rock pressure in the isolated island working face crossing the fault," Coal Engineering, vol. 50, no. S1, pp. 136-138, 2018.

[11] Z. Q. Wang, C. H. Xu, Y. J. Ren et al., "Research on roof failure mechanism under the influence of abutment pressure on isolated island working face," China Work Safety Science and Technology, vol. 15, no. 6, pp. 105-112, 2019.

[12] Y. X. Wang, J. B. Shen, and B. T. Fan, "Research on the relationship between impact hazard and micro-seismic activity of isolated island working face," Shandong Coal Science and Technology, vol. 5, pp. 161-162, 2013a.

[13] Q. Wang, S. H. Tu, Y. Yong, H. S. Tu, S. Wang, and F. Y. Feng, "Determination of reasonable coal pillar size for roadway protection in fully mechanized caving face of isolated island," Coal Mine Safety, vol. 45 01, pp. 36-39, 2014.

[14] W. J. Zhao, Y. L. Ma, Y. L. Liu, and G. W. Xu, "Research on characteristics of rock pressure in isolated island working face in shallow seam with large mining height," Coal Technology, vol. 38, no. 5, pp. 21-23, 2019.

[15] W. L. Yang, Q. D. Wei, X. C. Qu, W. X. Liu, and J. N. Zhang, "Classification and application research of isolated working face based on anti-flushing," China Work Safety Science and Technology, vol. 14, no. 12, pp. 107-113, 2018. 
[16] G. A. Zhu, L. M. Dou, Z. W. Ding, and J. H. Xie, "Pre-assessment research on shock hazard of isolated island working face before mining," Chinese Journal of Geotechnical Engineering, vol. 40, no. 5, pp. 819-827, 2018.

[17] L. M. Dou, Y. He, and W. D. Zhang, "Rock burst hazard and its control on isolated island working face," Chinese Journal of Rock Mechanics and Engineering, vol. 11, pp. 1866-1869, 2003.

[18] Y. D. Jiang, Y. S. Pan, F. X. Jiang, and L. M. Dou, "The mechanism and prevention of rock burst in coal mining in my country," Journal of China Coal Society, vol. 39, no. 2, pp. 205-213, 2014.

[19] Z. L. Li, X. Q. He, L. M. Dou, G. F. Wang, D. Z. Song, and Q. Lou, "The process of coal impact failure and the characteristics of acoustic and electrical response of the same source," Chinese Journal of Rock Mechanics and Engineering, vol. 38, no. 10, pp. 2057-2068, 2019.

[20] L. M. Dou, Z. L. Li, and M. Zhang, "Research on monitoring and early warning technology for coal mine rock burst disasters," Coal Science and Technology, vol. 44, no. 7, pp. 41-46, 2016.

[21] C. Wang, H. S. Tu, and Q. S. Bai, "The behavior of underground pressure in fully mechanized caving face with shortwall coal pillars in isolated island," Coal Mine Safety, vol. 44, no. 10, pp. 27-29, 2013b.

[22] H. W. Zhang, Y. Cao, F. Zhu, and L. F. Shao, "Rock burst mechanism and precursor identification of hard roof island working face," Coal Geology and Prospecting, vol. 46, no. 2, pp. 118-123, 2018. 